\title{
Cryptococcus yokohamensis sp. nov., a basidiomycetous yeast isolated from trees and a Queensland koala kept in a Japanese zoological park
}

\author{
Mohamed Mahdi Alshahni, ${ }^{1,2}$ Koichi Makimura, ${ }^{1}$ Kazuo Satoh, ${ }^{1}$ \\ Yayoi Nishiyama, ${ }^{1}$ Nobuhide Kido $^{3}$ and Takuo Sawada ${ }^{2}$ \\ ${ }^{1}$ Teikyo University Institute of Medical Mycology, 359 Otsuka, Hachioji, Tokyo 192-0395, Japan \\ ${ }^{2}$ Nippon Veterinary and Life Science University, 1-7-1 Sakaiminami, Musashino, Tokyo 180-8602, \\ Japan \\ ${ }^{3}$ Kanazawa Zoological Garden Animal Hospital, 5-15-1 Kamariya-higashi, Kanazawaku, \\ Yokohama 236-0042, Japan
}

\begin{abstract}
Three strains were isolated from the nostrils of a koala and the surrounding environment in a Japanese zoological park. Sequence analysis of the nuclear rDNA internal transcribed spacer (ITS) region and the large subunit rDNA D1/D2 domains in addition to physiological and morphological studies indicated that the isolates represent a single novel species belonging to the basidiomycetous genus Cryptococcus (Tremellales, Tremellomycetes, Agaricomycotina).

Phylogenetic analysis based on D1/D2 and ITS regions revealed that the novel species belongs to the Fuciformis clade. The name Cryptococcus yokohamensis sp. nov. is proposed to accommodate these isolates with strain JCM $16989^{\top}\left(=\right.$ TIMM $10001^{\top}=$ CBS $11776^{\top}=$ DSM $23671^{\top}$ ) as the type strain.
\end{abstract}

The genus Cryptococcus Vuillemin includes anamorphic basidiomycetous yeasts that are characterized by the presence of coenzymes Q-9 and Q-10, positivity for urease and diazonium blue $\mathrm{B}$ reactions, the absence of fermentation, the presence of xylose in cell-wall hydrolysates and the ability to assimilate D-glucuronate (Fell \& Statzell-Tallman, 1998). Furthermore, most species of the genus produce extracellular starch-like compounds. Species forming the polyphyletic genus Cryptococcus are dispersed in the orders Tremellales, Trichosporonales, Filobasidiales and Cystofilobasidiales (Fell et al., 2000; Golubev et al., 2006).

In the present study, isolation of three novel basidiomycetous yeast strains during a yeast survey of the Kanazawa Zoological Park in Yokohama city, Japan, is reported. Sequence analysis of the large subunit rDNA D1/D2 domains showed that the strains represent a single species $(99 \%$ similarity), which was genetically distinct from other species of the Tremellales. The isolates were considered to belong to the genus Cryptococcus based on physiological, morphological

\section{Abbreviation: ITS, internal transcribed spacer.}

The GenBank/EMBL/DDBJ accession numbers for the 26S rDNA D1/D2 domain and ITS sequences of JCM $16989^{\top}$ are HM222927 and HM222926, respectively.

A supplementary figure is available with the online version of this paper. and molecular features. In this paper, the novel species Cryptococcus yokohamensis sp. nov. is described.

Strains JCM 16990 and JCM $16989^{\mathrm{T}}$ were isolated from the trunk of trees (Eucalyptus spp.), whereas strain JCM 16991 was isolated from the nostril of a Queensland koala (Phascolarctos cinereus) kept in a Kanazawa zoo. The nasal smear was sampled with sterilized swabs and then inoculated onto CHROMagar Candida. Morphological, biochemical and physiological characterizations of the isolates were performed using the methods and protocols described by Yarrow (1998). The presence of a capsule was demonstrated by microscopic examination of cells mounted in dilute Indian ink. Scanning electron microscopy of the isolate was performed as described previously (Nishiyama et al., 2005). Two media were used to test mating compatibility among the three isolates as described previously (Bandoni, 1963; Kwon-Chung, 1976).

For molecular biological identification, direct colony PCR (Alshahni et al., 2009) was used to amplify the internal transcribed spacer (ITS) region and the $26 \mathrm{~S}$ rDNA D1/D2 domains using two pairs of primers, ITS1/ITS4 and 28SF1/ 635, respectively (Mirhendi et al., 2005; Sugita et al., 2003; White et al., 1990). Amplified fragments were sequenced with an Applied Biosystems model 3130 sequencer. Phylogenetic analysis according to the neighbour-joining 
method (Saitou \& Nei, 1987) was performed with MEGA 4.0.2 software (Tamura et al., 2007). A set of 38 taxa which included the major clades in the Tremellales (Scorzetti et al., 2002) was used to construct phylogenetic trees. Data consistency was tested by bootstrapping the alignments with 1000 replicates with correction for multiple substitutions. The quinone profile was determined by TechnoSuruga Laboratory (Shizuoka, Japan). Extraction and purification of the coenzyme Q system was performed according to Yamada \& Kondo (1973). HPLC (Waters 600 series) was used to identify coenzyme Q.

\section{Species delineation and classification}

Sequence comparison of the ITS and D1/D2 domains of the three isolates showed high levels of similarity and confirmed their conspecificity. A similarity search of these regions using BLAST indicated that the isolated strains represent a novel yeast species.

Tremella species are found in four main clades in the phylogenetic trees constructed based on ITS and D1/D2 regions (Scorzetti et al., 2002). The three strains of Cryptococcus yokohamensis sp. nov. clustered in the Fuciformis clade as shown in trees generated for the D1/D2 (Fig. 1) and ITS (Supplementary Fig. S1 available in IJSEM Online) regions. The strains appear to be related to Tremella species, similar to Cryptococcus skinneri, which is in the Foliacea clade (Scorzetti et al., 2002). Strains of the novel yeast species were isolated from the trunk of trees and the nostril of a koala bear. The latter isolation might be fortuitous and the result of contamination of the animal from its feeding site. Many other Tremella species have been recovered from trees.

Phenotypic characteristics of this yeast are consistent with the current phenotypic characteristics of the genus Cryptococcus (Fell \& Statzell-Tallman, 1998), i.e. utilization of D-glucuronate, production of extracellular starch, the absence of fermentation, and Q-9 and Q-10 as major coenzymes. Moreover, the novel yeast is distinct from other basidiomycetous genera in the absence of ballistoconidia (Udeniomyces, Bensingtonia, Sporobolomyces and Bullera) or by the absence of hyphae (Trichosporon, Moniliella and Hyalodendron). In addition, buds of the novel yeast are not presented on elongated stalks unlike some basidiomycetes (Kockovaella, Sterigmatosporidium, Fellomyces, Tsuchiyaea, Kurtzmanomyces and Sterigmatomyces). Moreover, the isolates differ from Phaffia species by the absence of fermentation and from Rhodotorula species by production of starch-like compounds and assimilation of myo-inositol. Therefore, despite their relatedness to Tremella species, the anamorphic isolates were assigned to the genus Cryptococcus based on the key identification features of basidiomycetes, morphological characterization of the type strain and the absence of any sexual structures of Tremellales formed during mating tests for 30 days of incubation at $28{ }^{\circ} \mathrm{C}$ (data not shown).

It is noteworthy that even though C. yokohamensis sp. nov. shares most of the phenotypic properties of the genus Cryptococcus, i.e. possesses a capsule, utilizes D-glucuronate and produces extracellular starch, it has two major coenzymes, Q-9 (38.1\%) and Q-10 (61.9\%). This has not been reported previously in any tremellaceous Cryptococcus species, whereas Tremella mesenterica and Tremella coalescens are known to have both Q-9 and Q-10 (Vancanneyt et al., 1994). Furthermore, the ability of our novel strains to grow with $0.1 \%$ cycloheximide is also found in some Tremella species but is rarely observed in Cryptococcus species (Barnett et al., 2000). Although the novel isolates are phenotypically best accommodated in the genus Cryptococcus, other unique properties may warrant further taxonomic consideration and classification in a new genus. Therefore, the discovery of new related strains would be desirable to complete the sexual cycle and the description of this novel species.

\section{Latin diagnosis of Cryptococcus yokohamensis Alshahni, Satoh et Makimura sp. nov.}

In medio extracto fermenti et extracto malti confecto, post dies tres as $28{ }^{\circ} \mathrm{C}$, cellulae incapsulatae, globosae ad cylindricae $(1.7-2.4 \times 2.4-3.5 \mu \mathrm{m})$. In agaro malti post dies decem ad $28{ }^{\circ} \mathrm{C}$, striis coloro, glabra, nitida, mucosa, margo integra. Ballistoconidia nulla. Pseudohyphae nullae. Non fermentat. Assimilat sic: glucosum, D-galactosum, L-sorbosum, saccharosum, maltosum, cellobiosum, trehalosum, raffinosum, melezitosum, inulin (exigue), amylum solubile, D-xylosum, L-arabinosum, D-arabinosum, D-ribosum, Lrhamnosum (exigue), $N$-acetyl-D-glucosaminum, ethanolum, erythritolum, ribitolum, galactitolum, D-mannitolum, methyl $\alpha$-D-glucosidium, salicinum, acidum gluconicum, acidum succinicum, acidum citricum, inositolum (exigue), D-glucuronatum et $\mathrm{D}$-glucitolum; non respondent lactosum, melibiosum, methanolum, glycerolum, acidum DL-lacticum, hexadecanum nec 2-ketogluconatum. L-Lysinum, cadaverinum, ethylaminum et ammonium sulfatum assimilantur at non natrium nitrosum nec kalium nitricum. In medio sine vitaminis externis non crescit. Augmentum in $28{ }^{\circ} \mathrm{C}$; non crescit in $42{ }^{\circ} \mathrm{C}$. Materia amyloidea iodophila formantur. Reactiones diazonium caeruleum $B$ et ureasii positivae. Crescere potest in medio $0.1 \%$ cycloheximido addito et $10 \% \mathrm{NaCl}+5 \%$ glucose, non respondet $50 \%(\mathrm{w} / \mathrm{w}) \mathrm{GY}$ medio. Ubiquinonum majus: Q-9 et Q-10. Typus stirps JCM $16989^{\mathrm{T}}$ ex arbor, Japonia, isolata est. In collectionibus culturarum quas Japan Collection of Microorganisms, Wako, Saitama, sustentant, no. JCM $16989^{\mathrm{T}}$, Teikyo Institute of Medical Mycology, Hachioji, Tokyo, sustentant, no. TIMM $10001^{\mathrm{T}}$, Centraalbureau voor Schimmelcultures, Utrecht, Neerlandia, sustentant, no. CBS $11776^{\mathrm{T}}$, et Deutsche Sammlung von Mikroorganismen und Zellkulturen, Braunschweig, Germany sustentant, no. DSM $23671^{\mathrm{T}}$, deposita est.

\section{Description of Cryptococcus yokohamensis Alshahni, Satoh \& Makimura sp. nov.}

Cryptococcus yokohamensis (yo.ko.ha.men'sis. N.L. masc. adj. yokohamensis of or belonging to Yokohama, referring to the name of the place where Kanazawa Zoological Park is located and the isolates were obtained). 


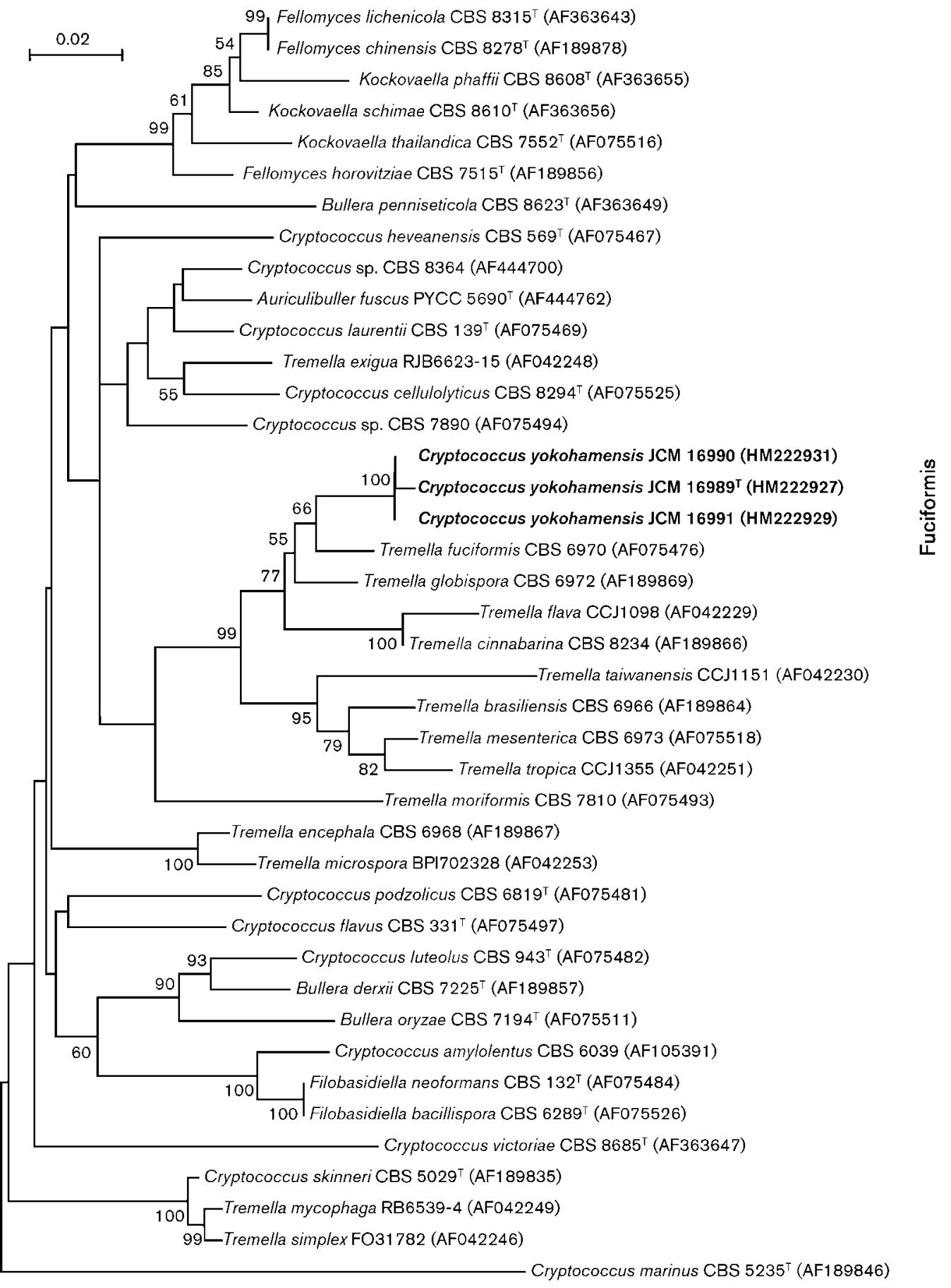

Fig. 1. Phylogenetic tree drawn from neighbour-joining analysis of $26 S$ rDNA D1/D2 domain sequences depicting the relationships of Cryptococcus yokohamensis sp. nov. with closely related species. Numbers on branches are bootstrap percentages ( $\geqslant 50 \%$ ). Cryptococcus marinus CBS $5235^{\top}$ is the outgroup. Bar, 2 substitutions per 100 nucleotide positions.

After 3 days in $5 \%$ malt extract at $28{ }^{\circ} \mathrm{C}$, cells are capsulated, globose to elongate $(1.7-2.4 \times 2.4-3.5 \mu \mathrm{m})$. Polar budding is observed and cells occur as parent bud pairs (Fig. 2). After 10 days on YM agar at $28{ }^{\circ} \mathrm{C}$, colonies are glistening, slimy, mucoid and tan with an entire margin. Pseudohyphae are not formed in Dalmau plate cultures on cornmeal. On cornmeal agar, ballistoconidia are not formed. Fermentation is absent. The following carbon compounds are assimilated: glucose, galactose, L-sorbose, sucrose, maltose, cellobiose, trehalose, raffinose, melezitose, inulin (weak), soluble starch, xylose, L-arabinose, D-arabinose, ribose, L-rhamnose (weak), $\mathrm{N}$-acetyl-D-glucosamine, ethanol, erythritol, ribitol, galactitol, 


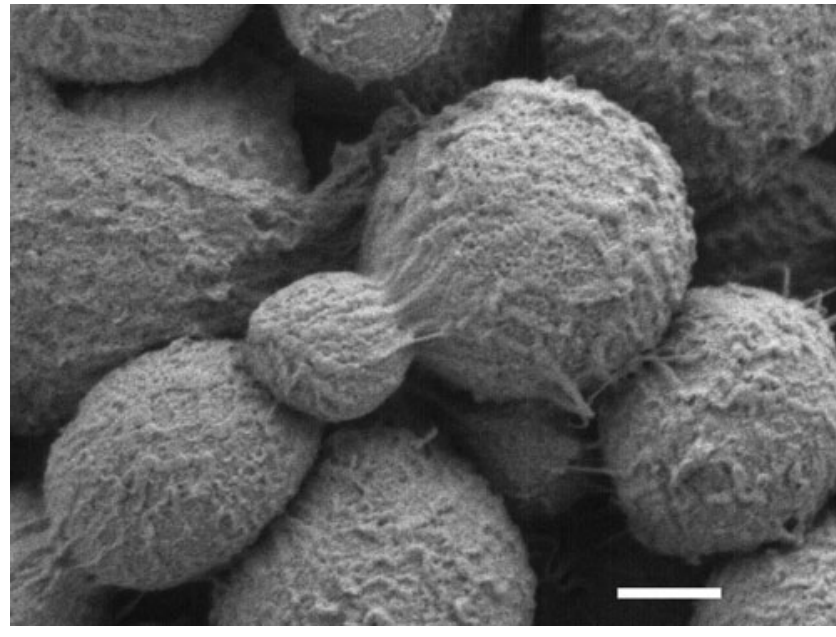

Fig. 2. Scanning electron micrograph of cells indicating polar budding of globose to elongated cells. Cells were grown on YM agar for 2 days before being processed for scanning electron microscopy. Bar, $1 \mu \mathrm{m}$.

mannitol, methyl $\alpha$-D-glucoside, salicin, D-gluconate, succinate, citrate, inositol (weak), D-glucuronate and sorbitol. The following are not assimilated: lactose, melibiose, methanol, glycerol, DL-lactate, hexadecane and 2-keto-D-gluconate. LLysine, cadaverine, ethylamine and ammonium sulphate are utilized as nitrogen sources, but not sodium nitrite or potassium nitrate. Growth in vitamin-free medium is negative. Optimal growth temperature is $28{ }^{\circ} \mathrm{C}$; delayed growth occurs at $37{ }^{\circ} \mathrm{C}$ but no growth is seen at $42{ }^{\circ} \mathrm{C}$. Starch-like compounds are formed. Urease activity is positive. Diazonium blue $B$ reaction is positive. Growth is observed in the presence of $0.1 \%(\mathrm{w} / \mathrm{v})$ cycloheximide and in $10 \%$ sodium chloride/ $5 \%$ glucose media, but not in $50 \%$ glucose. Major ubiquinones are Q-9 and Q-10.

The type strain is JCM $16989^{\mathrm{T}}\left(=\right.$ TIMM $10001^{\mathrm{T}}=\mathrm{DSM}$ $23671^{\mathrm{T}}=$ CBS $11776^{\mathrm{T}}$ ), isolated from the trunk of a Eucalyptus tree in Kanazawa Zoological Park (Yokohama, Japan).

\section{Acknowledgements}

We thank Mrs Yayoi Hasumi for her valuable technical assistance in preparation of samples for scanning electron microscopy examination. This study was supported in part by Health Science Research Grants for Research on Emerging and Re-emerging Infectious Diseases from the Ministry of Health, Labour and Welfare of Japan (K. M.).

\section{References}

Alshahni, M. M., Makimura, K., Yamada, T., Satoh, K., Ishihara, Y., Takatori, K. \& Sawada, T. (2009). Direct colony PCR of several medically important fungi using Ampdirect plus. Jpn J Infect Dis 62, 164-167.

Bandoni, R. J. (1963). Conjugation in Tremella mesenterica. Can J Bot 41, 467-474.

Barnett, J. A., Payne, R. W. \& Yarrow, D. (2000). Yeasts: Characteristics and Identification, 3rd edn. Cambridge: Cambridge University Press.

Fell, J. W. \& Statzell-Tallman, A. (1998). Cryptococcus Vuillemin. In The Yeasts, a Taxonomic Study, 4th edn, pp. 742-767. Edited by C. P. Kurtzman \& J. W. Fell. Amsterdam: Elsevier.

Fell, J. W., Boekhout, T., Fonseca, A., Scorzetti, G. \& StatzellTallman, A. (2000). Biodiversity and systematics of basidiomycetous yeasts as determined by large-subunit rDNA D1/D2 domain sequence analysis. Int J Syst Evol Microbiol 50, 1351-1371.

Golubev, W. I., Sampaio, J. P., Alves, L. \& Golubeva, E. W. (2006). Cryptococcus silvicola nov. sp. from nature reserves of Russia and Portugal. Antonie van Leeuwenhoek 89, 45-51.

Kwon-Chung, K. J. (1976). A new species of Filobasidiella, the sexual state of Cryptococcus neoformans B and C serotypes. Mycologia 68, 942-946.

Mirhendi, H., Makimura, K., Zomorodian, K., Maeda, N., Ohshima, T. \& Yamaguchi, H. (2005). Differentiation of Candida albicans and Candida dubliniensis using a single-enzyme PCR-RFLP method. Jpn J Infect Dis 58, 235-237.

Nishiyama, Y., Hasumi, Y., Ueda, K., Uchida, K. \& Yamaguchi, H. (2005). Effects of micafungin on the morphology of Aspergillus fumigatus. J Electron Microsc (Tokyo) 54, 67-77.

Saitou, N. \& Nei, M. (1987). The neighbor-joining method: a new method for reconstructing phylogenetic trees. Mol Biol Evol 4, 406425.

Scorzetti, G., Fell, J. W., Fonseca, A. \& Statzell-Tallman, A. (2002). Systematics of basidiomycetous yeasts: a comparison of large subunit D1/D2 and internal transcribed spacer rDNA regions. FEM Yeast Res 2, 495-517.

Sugita, C., Makimura, K., Murakami, A., Murai, Y., Yamaguchi, H. \& Nagai, A. (2003). A case of pulmonary aspergilloma molecular biological identification and typing of the isolates from antemortem sputa and autopsy fungus ball. Mycoses 46, 149-152.

Tamura, K., Dudley, J., Nei, M. \& Kumar, S. (2007). MEGA4: Molecular Evolutionary Genetics Analysis (MEGA) software version 4.0. Mol Biol Evol 24, 1596-1599.

Vancanneyt, M., Coopman, R., Tytgat, R., Hennebert, G. L. \& Kersters, K. (1994). Whole-cell protein patterns, DNA base compositions and coenzyme Q types in the yeast genus Cryptococcus Kützing and related taxa. Syst Appl Microbiol 17, 65-75.

White, T. J., Bruns, T., Lee, S. \& Taylor, J. (1990). Amplification and direct sequencing of fungal ribosomal RNA genes for phylogenetics. In PCR Protocols: a Guide to Methods and Applications, pp. 315-322. Edited by M. A. Innis, D. H. Gelfand, J. J. Sninsky \& T. J. White. New York: Academic Press.

Yamada, Y. \& Kondo, K. (1994). Coenzyme Q system in the classification of the yeast genera Rhodotorula and Cryptococcus and the yeast like genera Sporobolomyces and Rhodosporidium. J Gen Appl Microbiol 19, 59-77.

Yarrow, D. (1998). Methods for the isolation, maintenance and identification of yeasts. In The Yeasts, a Taxonomic Study, 4th edn, pp. 77-100. Edited by C. P. Kurtzman \& J. W. Fell. Amsterdam: Elsevier. 